\title{
Comparison of Effects of Rosuvastatin and Atorvastatin on Plaque Regression in Korean Patients With Untreated Intermediate Coronary Stenosis
}

Young Joon Hong, MD; Myung Ho Jeong, MD; Daisuke Hachinohe, MD; Khurshid Ahmed, MD; Yun Ha Choi; Sook Hee Cho, PhD; Seung Hwan Hwang, MD; Jum Suk Ko, MD; Min Goo Lee, MD; Keun Ho Park, MD; Doo Sun Sim, MD; Nam Sik Yoon, MD; Hyun Ju Yoon, MD; Kye Hun Kim, MD; Hyung Wook Park, MD; Ju Han Kim, MD; Youngkeun Ahn, MD; Jeong Gwan Cho, MD; Jong Chun Park, MD; Jung Chaee Kang, MD

\begin{abstract}
Background: Serial intravascular ultrasound (IVUS) was used to compare the effects of moderate doses of rosuvastatin and atorvastatin on plaque regression in patients with intermediate coronary stenosis.
\end{abstract}

\begin{abstract}
Methods and Results: This was a prospective, randomized, and comparative study for lipid-lowering therapy with rosuvastatin $20 \mathrm{mg}(\mathrm{n}=65)$ and atorvastatin $40 \mathrm{mg}(\mathrm{n}=63)$ using serial IVUS (baseline and 11-month follow-up). Efficacy parameters included changes in total atheroma volume (TAV) and percent atheroma volume (PAV) from baseline to follow-up. Changes of TAV $\left(-4.4 \pm 7.3\right.$ vs. $\left.-3.6 \pm 6.8 \mathrm{~mm}^{3}, P=0.5\right)$ and PAV $(-0.73 \pm 2.05$ vs. $-0.19 \pm 2.00 \%$, $\mathrm{P}=0.14$ ) from baseline to follow-up were not significantly different between the 2 groups. Plaque was increased in $15 \%$ in the rosuvastatin group and in $30 \%$ in the atorvastatin group at follow-up ( $P=0.064)$. The plaque increase group had higher baseline high-sensitivity C-reactive protein (hs-CRP; $1.28 \pm 2.70 \mathrm{mg} / \mathrm{dl}$ vs. $0.54 \pm 1.16 \mathrm{mg} / \mathrm{dl}$, $\mathrm{P}=0.034)$ and higher follow-up low-density lipoprotein cholesterol (LDL-C) $(78 \pm 24 \mathrm{mg} / \mathrm{dl}$ vs. $63 \pm 21 \mathrm{mg} / \mathrm{dl}, \mathrm{P}=0.002)$ compared with the plaque non-increase group. Follow-up LDL-C (odds ratio $[O R]=1.038,95 \%$ confidence interval $[\mathrm{Cl}]=1.003-1.060, \mathrm{P}=0.036)$ and baseline hs-CRP $(\mathrm{OR}=1.025,95 \% \mathrm{Cl}=1.001-1.059, \mathrm{P}=0.046)$, not the type of statin, were the independent predictors of plaque increase at follow-up.
\end{abstract}

Conclusions: Moderate doses of rosuvastatin and atorvastatin could contribute to effective plaque regression. Follow-up LDL-C and baseline hs-CRP are associated with plaque progression in patients with intermediate coronary stenosis. (Circ J 2011; 75: 398-406)

Key Words: Coronary disease; Intravascular ultrasound; Lipid; Plaque

$\mathbf{L}$ ipid-lowering therapy with statins improves clinical outcomes, $, 1,2$ and reduces the progression of atherosclerosis. ${ }^{3-5}$ Previous studies have demonstrated that statin therapy could induce regression of coronary atherosclerosis and that there was a strong linear relationship between achieved low-density lipoprotein cholesterol (LDLC) levels and the course of atherosclerosis. ${ }^{6-8}$ So far, no study has compared the effects of rosuvastatin and atorvastatin on plaque changes. Our hypothesis was that only moderate doses of statins could contribute to effective LDL-C lowering and plaque regression in Asian patients. Therefore, the primary purpose of the present study was to compare the effect of a moderate dose of rosuvastatin with that of atorvastatin on plaque regression in untreated intermediate coronary stenosis in Korean patients.

It is not known which factors are associated with plaque progression in patients who use statins. The secondary purpose of the present study was to assess the impact of clinical findings, laboratory findings, and intravascular ultrasound (IVUS) findings on plaque progression in untreated intermediate coronary stenosis in patients who used moderate doses of rosuvastatin or atorvastatin.

Received July 9, 2010; revised manuscript received August 28, 2010; accepted September 21, 2010; released online December 9, 2010 Time for primary review: 24 days

Heart Center of Chonnam National University Hospital, Gwangju, Korea

Mailing address: Myung Ho Jeong, MD, PhD, FACC, FAHA, FESC, FSCAI, Professor, Principal Investigator of Korea Acute Myocardial Infarction Registry, Director of Heart Research Center Designated by Korea Ministry of Health and Welfare, Chonnam National University Hospital, 671 Jaebongro, Dong-gu, Gwangju 501-757, Korea. E-mail: myungho@chollian.net

ISSN-1346-9843 doi:10.1253/circj.CJ-10-0658

All rights are reserved to the Japanese Circulation Society. For permissions, please e-mail: cj@j-circ.or.jp 


\section{(A) Baseline}

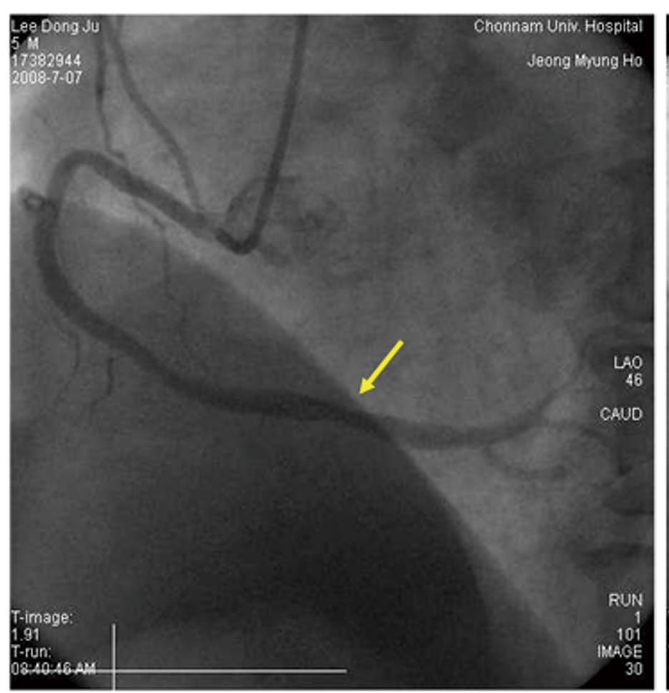

(B) Baseline

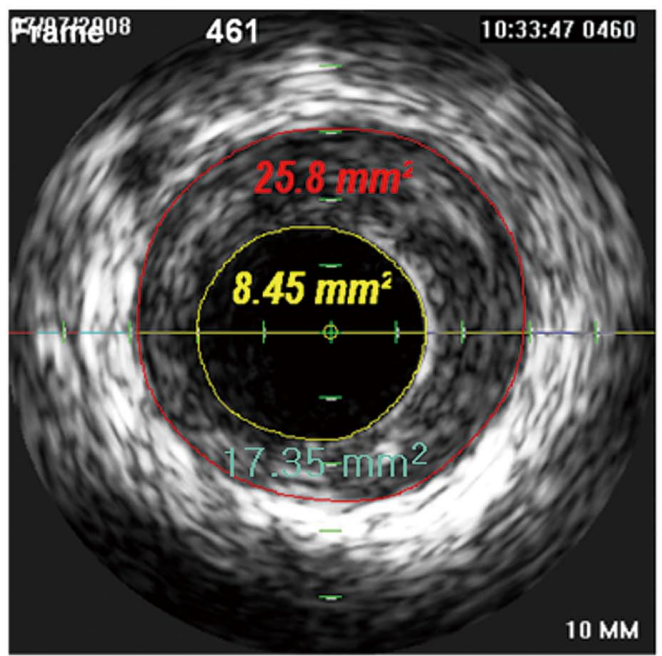

Plaque burden $67 \%$

\section{Follow up}

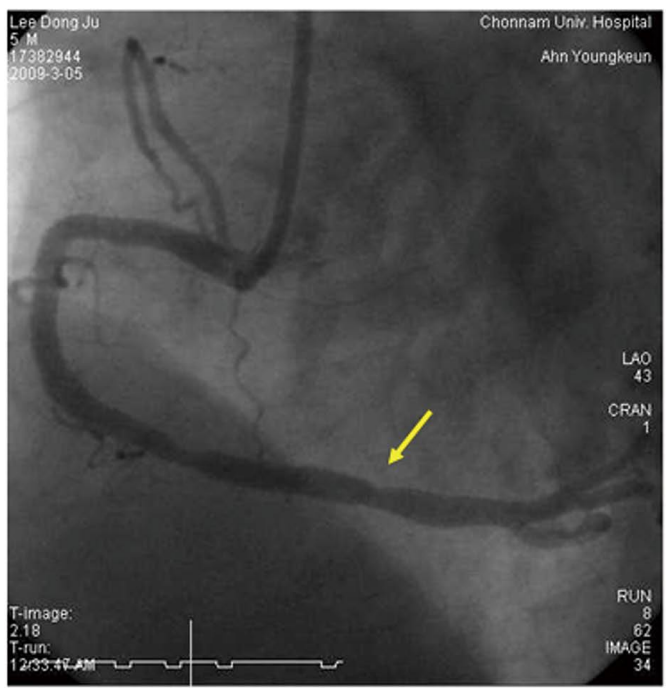

Follow up

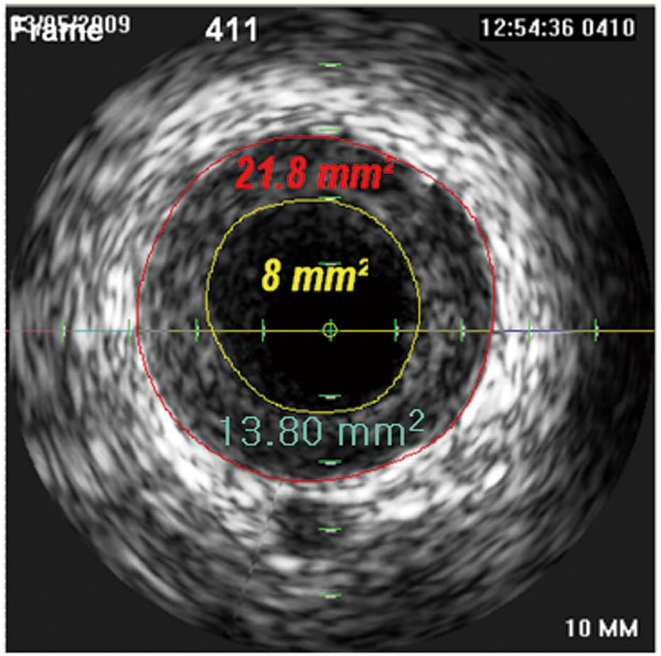

Plaque burden $63 \%$

Figure 1. (A) Coronary angiogram and (B) intravascular ultrasound of plaque regression due to statin therapy.

\section{Methods}

\section{Patients}

This study was a prospective, randomized, and comparative study of lipid-lowering therapy using moderate doses of rosuvastatin and atorvastatin in Korean patients with intermediate coronary stenosis, which was defined as diameter stenosis $30-70 \%$ on quantitative coronary angiography (QCA), at Chonnam National University Hospital, Gwangju, Korea. Patients were randomized to take either rosuvastatin $20 \mathrm{mg}$ or atorvastatin $40 \mathrm{mg}$ daily. Statin therapy was started immediately after coronary angiography (CAG) and IVUS in both groups. We excluded the patients with left ventricular dysfunction (ejection fraction $<30 \%$ ), and hepatic or renal dysfunction (alanine aminotransferase and aspartate aminotransferase $>2$-fold normal, creatinine $>1.5 \mathrm{mg} / \mathrm{dl}$ ). A total of 128 patients underwent baseline and 11-month follow-up CAG and IVUS (65 patients in the rosuvastatin group vs. 63 patients in the atorvastatin group). The protocol was approved by the institutional review board. Hospital records of patients were reviewed to obtain information on clinical demographics.

\section{Laboratory Analysis}

Peripheral blood samples were obtained before coronary angiography using direct venipuncture. The blood samples were centrifuged, and serum was removed and stored at $-70^{\circ} \mathrm{C}$ until the assay was performed. The serum levels of total cho- 


\begin{tabular}{|c|c|c|c|}
\hline & $\begin{array}{l}\text { Rosuvastatin } \\
\qquad(n=65)\end{array}$ & $\begin{array}{l}\text { Atorvastatin } \\
\quad(n=63)\end{array}$ & $P$ value \\
\hline Age (years) & $59 \pm 10$ & $58 \pm 10$ & 0.6 \\
\hline Male gender $(n)$ & $49(75)$ & $46(73)$ & 0.7 \\
\hline Clinical presentation $(n)$ & & & 0.10 \\
\hline Stable angina pectoris & $17(26)$ & $9(15)$ & \\
\hline Unstable angina pectoris & $29(45)$ & $33(52)$ & \\
\hline NSTEMI & $5(8)$ & $16(26)$ & \\
\hline STEMI & $14(22)$ & $5(8)$ & \\
\hline Hypertension (n) & $28(43)$ & $28(44)$ & 1.0 \\
\hline Diabetes mellitus ( $n$ ) & $12(19)$ & $18(29)$ & 0.16 \\
\hline Smoker $(\mathrm{n})$ & $24(37)$ & $18(29)$ & 0.4 \\
\hline Family history of coronary artery disease (n) & $1(2)$ & $1(2)$ & 1.0 \\
\hline Ejection fraction (\%) & $61 \pm 10$ & $64 \pm 9$ & 0.17 \\
\hline Total cholesterol (mg/dl) & $185 \pm 42$ & $181 \pm 43$ & 0.6 \\
\hline Triglyceride (mg/dl) & $125 \pm 94$ & $124 \pm 117$ & 0.9 \\
\hline LDL-C (mg/dl) & $122 \pm 37$ & $117 \pm 38$ & 0.5 \\
\hline HDL-C (mg/dl) & $47 \pm 10$ & $48 \pm 15$ & 0.7 \\
\hline Apoprotein A1 (mg/dl) & $127 \pm 16$ & $128 \pm 28$ & 0.7 \\
\hline Apoprotein B (mg/dl) & $95 \pm 24$ & $93 \pm 25$ & 0.6 \\
\hline Apoprotein B/A1 & $0.75 \pm 0.18$ & $0.75 \pm 0.28$ & 0.9 \\
\hline Lipoprotein (a) (mg/dl) & $29 \pm 21$ & $26 \pm 19$ & 0.4 \\
\hline $\mathrm{hs}-\mathrm{CRP}(\mathrm{mg} / \mathrm{dl})$ & $0.50 \pm 1.17$ & $0.93 \pm 2.03$ & 0.15 \\
\hline NT-pro-BNP (pg/ml) & $411 \pm 689$ & $315 \pm 711$ & 0.5 \\
\hline
\end{tabular}

Data are given as mean $\pm \mathrm{SD}$ or $\mathrm{n}(\%)$.

NSTEMI, non-ST segment elevation myocardial infarction; STEMI, ST segment elevation myocardial infarction; LDL-C, low-density lipoprotein cholesterol; HDL-C, high-density lipoprotein cholesterol; hs-CRP, high-sensitivity C-reactive protein; NT-pro-BNP, N-terminal pro-B-type natriuretic peptide.

lesterol, triglyceride, LDL-C, and high-density lipoprotein cholesterol were measured using standard enzymatic methods. High-sensitivity C-reactive protein (hs-CRP) was analyzed turbidimetrically with sheep antibodies against human CRP; this has been validated against the Dade-Behring method. ${ }^{9}$ Serum N-terminal pro-B-type natriuretic peptide was measured using an electrochemiluminescence sandwich immunoassay with an Elecsys 2010 analyzer (Roche Diagnostics, Mannheim, Germany).

\section{Angiography}

Coronary angiogram was analyzed with a validated QCA system (Phillips H5000 or Allura DCI program, Philips Medical Systems, Eindhoven, the Netherlands). ${ }^{10}$ With the outer diameter of the contrast-filled catheter as the calibration standard, the minimal lumen diameter and reference diameter were measured in diastolic frames from orthogonal projections.

\section{IVUS}

IVUS was performed after intra-coronary administration of $300 \mu \mathrm{g}$ nitroglycerin using a commercially available IVUS system (Boston Scientific/SCIMed, Minneapolis, MN, USA). The IVUS catheter was advanced distal to the target lesion, and imaging was performed retrograde to the aorto-ostial junction at an automatic pullback speed of $0.5 \mathrm{~mm} / \mathrm{s}$. IVUS data were analyzed by 2 independent observers (H.Y.J. and C.Y.H.). The levels of reproducibility for external elastic membrane (EEM) volume, lumen volume, and total atheroma volume (TAV) using the Spearman rank-order correlation coefficients were $0.95,0.97$, and 0.97 , respectively. We measured diseased segment (normal to normal). The same anatomic image slices were analyzed at baseline and at follow-up. By using the axial landmark (ie, side branch, calcifications, or unusual plaque shapes) and the known pullback speed, identical cross-sectional image slices on serial studies could be identified for comparison. We measured IVUS images spaced precisely $1 \mathrm{~mm}$ apart. The leading edges of the EEM and lumen were traced manually using planimetry software (Echoplaque 3.0, INDEC Systems, Santa Clara, CA, USA) in accordance with guidelines for IVUS from the American College of Cardiology Clinical Expert Consensus Document on Standards for Acquisition, Measurement and Reporting of Intravascular Ultrasound Studies. ${ }^{11}$ TAV was calculated by summation of atheroma area from each measured image as: TAV $=\Sigma($ EEM area-lumen area). The percent atheroma volume (PAV) was determined using the formula: $\mathrm{PAV}=100 \times[\Sigma($ EEM area-lumen area $) / \Sigma($ EEM area $)]$. Plaque increase was defined as increase of TAV from baseline to follow-up, and plaque non-increase was defined as decrease of TAV from baseline to follow-up (Figure 1). Soft plaque was less bright compared with the reference adventitia. Fibrotic plaque was as bright as or brighter than the reference adventitia without acoustic shadowing. Calcified plaque was hyperechoic with shadowing. A calcified lesion contained $>90^{\circ}$ of circumferential lesion calcium. When there was no dominant plaque composition, the plaque was classified as mixed.

\section{Statistical Analysis}

SPSS for Windows, version 15.0 (SPSS, Chicago, IL, USA) was used for all analyses. Continuous variables are presented 


\begin{tabular}{|c|c|c|c|}
\hline & $\begin{array}{l}\text { Rosuvastatin } \\
\qquad(n=65)\end{array}$ & $\begin{array}{l}\text { Atorvastatin } \\
\quad(n=63)\end{array}$ & $P$ value \\
\hline Target coronary artery $(n)$ & & & 0.10 \\
\hline Left main & $3(5)$ & $5(8)$ & \\
\hline Left anterior descending & $37(57)$ & $35(55)$ & \\
\hline Left circumflex & $4(6)$ & $11(18)$ & \\
\hline Right & $21(32)$ & $12(19)$ & \\
\hline Lesion location (n) & & & 0.5 \\
\hline Proximal & $32(49)$ & $33(52)$ & \\
\hline Middle & $21(32)$ & $20(32)$ & \\
\hline Distal & $12(18)$ & $10(16)$ & \\
\hline $\mathrm{RD}(\mathrm{mm})$ & $3.29 \pm 0.50$ & $3.26 \pm 0.48$ & 0.4 \\
\hline MLD (mm) & $1.77 \pm 0.44$ & $1.79 \pm 0.54$ & 0.8 \\
\hline Percent diameter stenosis (\%) & $46 \pm 10$ & $45 \pm 9$ & 0.9 \\
\hline IVUS lesion length (mm) & $17 \pm 10$ & $21 \pm 18$ & 0.10 \\
\hline Plaque morphology (n) & & & 0.4 \\
\hline Soft & $41(63)$ & $42(66)$ & \\
\hline Fibrotic & $3(5)$ & $5(8)$ & \\
\hline Calcified & $5(8)$ & $4(6)$ & \\
\hline Mixed & $16(25)$ & $12(19)$ & \\
\hline EEM volume $\left(\mathrm{mm}^{3}\right)$ & $346 \pm 194$ & $385 \pm 242$ & 0.3 \\
\hline Lumen volume $\left(\mathrm{mm}^{3}\right)$ & $180 \pm 107$ & $194 \pm 126$ & 0.5 \\
\hline $\operatorname{TAV}\left(\mathrm{mm}^{3}\right)$ & $166 \pm 93$ & $190 \pm 119$ & 0.2 \\
\hline PAV (\%) & $48.0 \pm 6.1$ & $49.9 \pm 6.1$ & 0.080 \\
\hline
\end{tabular}

Data are given as mean \pm SD or $\mathrm{n}(\%)$.

CAG, coronary angiography; IVUS, intravascular ultrasound; RD, reference diameter; MLD, minimal lumen diameter; EEM, external elastic membrane; TAV, total atheroma volume; PAV, percent atheroma volume.

as mean $\pm 1 \mathrm{SD}$; comparisons were done using Student's t-test or the Wilcoxon rank-sum test if normality assumption was violated. Discrete variables are presented as percentages and frequencies; comparisons were done using chi-squared statistics or Fisher's exact test as appropriate. Pearson's correlation coefficient was used to evaluate the associations between follow-up LDL-C vs. change in TAV and PAV and between baseline hs-CRP vs. change in TAV and PAV. Multivariable logistic regression analysis was performed to identify independent predictors of plaque increase at follow-up. $\mathrm{P}<0.05$ was considered statistically significant.

\section{Results}

\section{Baseline Characteristics}

Baseline characteristics are summarized in Table 1. There were no significant differences in age, gender, risk factors for coronary artery disease, ejection fraction, and baseline LDL$\mathrm{C}$ and hs-CRP between rosuvastatin and atorvastatin groups.

\section{CAG and IVUS}

Baseline CAG and IVUS findings are summarized in Table 2. There were no significant differences in target lesion, lesion location, minimal lumen diameter on QCA, IVUS lesion length, plaque morphology, TAV, or PAV between the rosuvastatin and atorvastatin groups.

\section{Follow-up Laboratory Tests and IVUS and Changes in Findings}

Follow-up laboratory tests and IVUS and changes in findings from baseline to follow-up are summarized in Table 3. There were no significant differences in follow-up LDL-C and hs-CRP between the rosuvastatin and atorvastatin groups. Follow-up TAV was not significantly different between the rosuvastatin and atorvastatin groups, but follow-up PAV was significantly smaller in the rosuvastatin group compared with the atorvastatin group. Changes of LDL-C and hs-CRP from baseline to follow-up were not significantly different, and changes of TAV and PAV from baseline to follow-up were not significantly different between the rosuvastatin and atorvastatin groups.

\section{Baseline Characteristics vs. Plaque Change}

Of 128 patients, plaque was increased in $29(23 \% ; 15 \%$ [10/65] in the rosuvastatin group vs. 30\% [19/63] in the atorvastatin group) and was decreased in 99 patients $(77 \% ; 85 \%$ [55/65] in the rosuvastatin group vs. 70\% [44/63] in the atorvastatin group) at 11 -month follow-up $(\mathrm{P}=0.064)$. The baseline characteristics according to plaque increase or non-increase are summarized in Table 4. The patients in the plaque increase group were significantly younger, had lower ejection fraction, higher baseline hs-CRP, and higher follow-up LDL-C compared with those in the plaque non-increase group. There was a trend towards greater plaque regression in patients with acute coronary syndrome compared to those with stable angina pectoris ( $\triangle \mathrm{TAV}:-6.0 \pm 8.8 \mathrm{~mm}^{3}$ vs. $-3.5 \pm 6.5 \mathrm{~mm}^{3}, \mathrm{P}=0.18 ; \Delta \mathrm{PAV}$ : $-1.03 \pm 2.32 \%$ vs. $-0.29 \pm 1.89 \%, \mathrm{P}=0.10$, respectively).

\section{CAG and IVUS vs. Plaque Change}

CAG and IVUS findings according to plaque change are summarized in Table 5. There were no significant differences in the target vessel, lesion location, or QCA data between the plaque increase and non-increase groups. There were no significant differences in baseline IVUS between 


\begin{tabular}{|c|c|c|c|}
\hline & $\begin{array}{l}\text { Rosuvastatin } \\
\quad(n=65)\end{array}$ & $\begin{array}{l}\text { Atorvastatin } \\
\quad(n=63)\end{array}$ & $P$ value \\
\hline Total cholesterol (mg/dl) & $124 \pm 25$ & $133 \pm 32$ & 0.092 \\
\hline Triglyceride (mg/dl) & $94 \pm 56$ & $103 \pm 193$ & 0.7 \\
\hline LDL-C (mg/dl) & $62 \pm 20$ & $70 \pm 24$ & 0.053 \\
\hline $\mathrm{HDL}-\mathrm{C}(\mathrm{mg} / \mathrm{dl})$ & $47 \pm 12$ & $47 \pm 12$ & 0.8 \\
\hline Apoprotein A1 (mg/dl) & $130 \pm 20$ & $126 \pm 22$ & 0.2 \\
\hline Apoprotein B (mg/dl) & $59 \pm 15$ & $60 \pm 19$ & 0.8 \\
\hline Apoprotein B/A1 & $0.46 \pm 0.13$ & $0.50 \pm 0.17$ & 0.15 \\
\hline Lipoprotein (a) (mg/dl) & $33 \pm 30$ & $28 \pm 23$ & 0.3 \\
\hline $\mathrm{hs}-\mathrm{CRP}(\mathrm{mg} / \mathrm{dl})$ & $0.10 \pm 0.14$ & $0.10 \pm 0.18$ & 1.0 \\
\hline EEM volume $\left(\mathrm{mm}^{3}\right)$ & $346 \pm 194$ & $385 \pm 242$ & 0.4 \\
\hline Lumen volume $\left(\mathrm{mm}^{3}\right)$ & $182 \pm 109$ & $194 \pm 126$ & 0.6 \\
\hline $\operatorname{TAV}\left(\mathrm{mm}^{3}\right)$ & $166 \pm 93$ & $190 \pm 119$ & 0.19 \\
\hline PAV (\%) & $47.3 \pm 6.5$ & $49.7 \pm 6.5$ & 0.035 \\
\hline$\Delta$ Total cholesterol $(\mathrm{mg} / \mathrm{dl})$ & $-61 \pm 38$ & $-48 \pm 47$ & 0.091 \\
\hline$\Delta$ Triglyceride $(\mathrm{mg} / \mathrm{dl})$ & $-31 \pm 79$ & $-19 \pm 108$ & 0.5 \\
\hline$\Delta \mathrm{LDL}-\mathrm{C}(\mathrm{mg} / \mathrm{dl})$ & $-60 \pm 33$ & $-47 \pm 39$ & 0.057 \\
\hline$\Delta \mathrm{HDL}-\mathrm{C}(\mathrm{mg} / \mathrm{dl})$ & $-0.5 \pm 9.1$ & $-1.1 \pm 11.3$ & 0.8 \\
\hline$\Delta$ Apoprotein A1 (mg/dl) & $+3.0 \pm 16.1$ & $-2.4 \pm 25.8$ & 0.18 \\
\hline$\Delta$ Apoprotein B (mg/dl) & $-36 \pm 22$ & $-34 \pm 25$ & 0.7 \\
\hline$\Delta$ Apoprotein B/A1 & $-0.29 \pm 0.11$ & $-0.25 \pm 0.10$ & 0.18 \\
\hline$\Delta$ Lipoprotein (a) (mg/dl) & $+5.5 \pm 13.8$ & $+2.5 \pm 10.5$ & 0.18 \\
\hline$\Delta \mathrm{hs}-\mathrm{CRP}(\mathrm{mg} / \mathrm{dl})$ & $-0.40 \pm 1.18$ & $-0.84 \pm 2.07$ & 0.16 \\
\hline$\triangle \mathrm{EEM}$ volume $\left(\mathrm{mm}^{3}\right)$ & $-3.1 \pm 7.9$ & $-5.1 \pm 9.5$ & 0.2 \\
\hline$\Delta$ lumen volume $\left(\mathrm{mm}^{3}\right)$ & $+1.3 \pm 7.1$ & $-1.0 \pm 7.3$ & 0.070 \\
\hline$\Delta \operatorname{TAV}\left(\mathrm{mm}^{3}\right)$ & $-4.4 \pm 7.3$ & $-3.6 \pm 6.8$ & 0.5 \\
\hline$\triangle \mathrm{PAV}(\%)$ & $-0.73 \pm 2.05$ & $-0.19 \pm 2.10$ & 0.14 \\
\hline
\end{tabular}

Abbreviations see in Table 1.

the plaque increase and non-increase groups.

\section{Follow-up Laboratory Tests and IVUS and Changes in Findings vs. Plaque Changes}

Follow-up laboratory tests and IVUS and changes in findings from baseline to follow-up according to plaque increase or non-increase are summarized in Table 6. Follow-up total cholesterol, triglyceride, LDL-C, apoprotein B, and apoprotein B/A1 were significantly higher in the plaque increase group compared with the plaque non-increase group. Changes in total cholesterol, triglyceride, LDL-C, high-density lipoprotein cholesterol, and hs-CRP levels from baseline to follow-up were not significantly different between the plaque increase and non-increase groups. EEM volume increased in the plaque increase group and decreased in the plaque non-increase group from baseline to follow-up.

\section{Plaque Increase vs. Follow-up LDL-C, and Baseline and Follow-up hs-CRP}

Plaque was increased in $34 \%$ of patients with follow-up LDLC $>70 \mathrm{mg} / \mathrm{dl}(17 / 50)$ and in $15 \%$ of patients with follow-up LDL-C $\leq 70 \mathrm{mg} / \mathrm{dl}$ (12/78; $\mathrm{P}=0.014$; Figure 2A). Plaque was increased in $38 \%$ of patients with baseline hs-CRP $\geq 1.0 \mathrm{mg} / \mathrm{dl}$ $(6 / 16)$ and in $21 \%$ of patients with baseline hs-CRP $<1.0 \mathrm{mg} / \mathrm{dl}$ (23/112; $\mathrm{P}=0.020$; Figure 2B). Plaque was increased in $37 \%$ of patients with follow-up hs-CRP $\geq 0.1 \mathrm{mg} / \mathrm{dl}(11 / 30)$ and in $18 \%$ of patients with follow-up hs-CRP $<0.1 \mathrm{mg} / \mathrm{dl}(18 / 98$; $\mathrm{P}=0.045$; Figure 2C).

There were positive correlations between follow-up LDL-
$\mathrm{C}$ and $\triangle \mathrm{TAV}(\mathrm{r}=0.274, \mathrm{P}=0.003)$, and follow-up LDL-C and $\triangle \mathrm{PAV}(\mathrm{r}=0.225, \mathrm{P}=0.014)$. There were positive correlations between baseline hs-CRP and $\Delta \mathrm{TAV}(\mathrm{r}=0.234, \mathrm{P}=0.011)$, and baseline hs-CRP and $\triangle \mathrm{PAV}(\mathrm{r}=0.212, \mathrm{P}=0.021)$.

\section{Independent Predictors of Plaque Increase}

The following variables were tested to determine the independent predictors of plaque increase at follow-up (variables with $\mathrm{P}<0.1$ in univariate analysis): type of statin, age, ejection fraction, baseline hs-CRP, baseline apoprotein B/A1, baseline TAV, and follow-up LDL-C. Follow-up LDL-C (odds ratio $[\mathrm{OR}]=1.038,95 \%$ confidence interval $[\mathrm{CI}]=1.003-1.060$, $\mathrm{P}=0.036)$ and baseline hs-CRP $(\mathrm{OR}=1.025$, 95\%CI=1.001$1.059, \mathrm{P}=0.046$ ), but not type of statin, were the independent predictors of plaque increase at follow-up.

\section{Discussion}

The present serial IVUS study has demonstrated that (1) changes in LDL-C and hs-CRP from baseline to follow-up were not significantly different, and changes of TAV and PAV from baseline to follow-up were not significantly different between rosuvastatin and atorvastatin groups; (2) plaque was decreased in $85 \%$ of patients in the rosuvastatin group and in $70 \%$ of patients in the atorvastatin group at 11month follow-up; and (3) follow-up LDL-C and baseline hsCRP, but not type of statin, were the independent predictors of plaque increase at follow-up. Moderate doses of rosuvastatin and atorvastatin could contribute to effective plaque 


\begin{tabular}{|c|c|c|c|}
\hline & $\begin{array}{l}\text { Plaque increase } \\
\qquad(n=29)\end{array}$ & $\begin{array}{l}\text { Plaque non-increase } \\
\qquad(n=99)\end{array}$ & $P$ value \\
\hline Type of statin (n) & & & 0.064 \\
\hline Rosuvastatin & $10(15)$ & $55(85)$ & \\
\hline Atorvastatin & $19(30)$ & $44(70)$ & \\
\hline Age (years) & $54 \pm 10$ & $59 \pm 10$ & 0.011 \\
\hline Male gender (n) & $20(69)$ & $75(76)$ & 0.5 \\
\hline Clinical presentation (n) & & & 0.6 \\
\hline Stable angina pectoris & $6(21)$ & $20(20)$ & \\
\hline Unstable angina pectoris & $11(38)$ & $50(51)$ & \\
\hline NSTEMI & $6(21)$ & $15(15)$ & \\
\hline STEMI & $6(21)$ & $14(14)$ & \\
\hline Hypertension (n) & $11(38)$ & $45(46)$ & 0.5 \\
\hline Diabetes mellitus ( $n$ ) & $6(21)$ & $24(24)$ & 0.7 \\
\hline Smoker $(n)$ & $11(38)$ & $32(32)$ & 0.7 \\
\hline Family history of coronary artery disease (n) & $2(7)$ & $0(0)$ & 0.2 \\
\hline Ejection fraction (\%) & $58 \pm 12$ & $64 \pm 9$ & 0.038 \\
\hline Total cholesterol (mg/dl) & $193 \pm 50$ & $182 \pm 41$ & 0.2 \\
\hline Triglyceride (mg/dl) & $145 \pm 161$ & $118 \pm 81$ & 0.2 \\
\hline LDL-C (mg/dl) & $126 \pm 40$ & $118 \pm 37$ & 0.3 \\
\hline $\mathrm{HDL}-\mathrm{C}(\mathrm{mg} / \mathrm{dl})$ & $50 \pm 19$ & $47 \pm 10$ & 0.5 \\
\hline Apoprotein A1 (mg/dl) & $128 \pm 30$ & $127 \pm 19$ & 0.9 \\
\hline Apoprotein B (mg/dl) & $101 \pm 26$ & $92 \pm 24$ & 0.085 \\
\hline Apoprotein B/A1 & $0.83 \pm 0.27$ & $0.73 \pm 0.22$ & 0.060 \\
\hline Lipoprotein (a) (mg/dl) & $28 \pm 18$ & $27 \pm 20$ & 0.8 \\
\hline $\mathrm{hs}-\mathrm{CRP}(\mathrm{mg} / \mathrm{dl})$ & $1.28 \pm 2.70$ & $0.54 \pm 1.16$ & 0.034 \\
\hline NT-pro-BNP (pg/ml) & $561 \pm 965$ & $310 \pm 585$ & 0.2 \\
\hline \multicolumn{4}{|l|}{ Medications at discharge (n) } \\
\hline Aspirin & $27(93)$ & $94(95)$ & 0.8 \\
\hline Clopidogrel & $12(41)$ & $38(38)$ & 0.7 \\
\hline ACEI/ARB & $11(38)$ & $45(46)$ & 0.5 \\
\hline$\beta$-blockers & $11(38)$ & $32(32)$ & 0.7 \\
\hline Calcium-channel blockers & $20(69)$ & $64(64)$ & 0.5 \\
\hline
\end{tabular}

Data are given as mean \pm SD or $n(\%)$.

ACEI/ARB, angiotensin-converting enzyme inhibitor/angiotensin receptor blocker. Other abbreviations see in Tables 1 , 2.

regression, and follow-up LDL-C and baseline hs-CRP are associated with plaque progression in Korean patients with untreated intermediate coronary stenosis. This therefore suggests that different types of statins with similar efficacy in LDL-C and hs-CRP reduction have similar effects on plaque regression at follow-up.

IVUS is a useful tool for assessing the effect of therapies on the vascular wall, providing a precise and continuous measure of disease progression. ${ }^{12}$ The recent REVERSal of Atherosclerosis with Lipitor (REVERSAL) study showed that plaque volume progression was smaller with aggressive statin treatment with atorvastatin $80 \mathrm{mg}$ daily than moderate statin treatment with pravastatin $40 \mathrm{mg}$ daily. ${ }^{6}$ And the A Study to Evaluate the Effect of Rosuvastatin on Intravascular Ultrasound-derived Coronary Atheroma Burden (ASTEROID) trial demonstrated that intensive statin therapy with rosuvastatin $40 \mathrm{mg}$ daily could induce regression of coronary atherosclerosis. ${ }^{7}$ Previous studies have shown that there is a very strong linear relationship between achieved LDL-C levels and the course of atherosclerosis. ${ }^{3-8}$ In the present study, $20 \mathrm{mg}$ of rosuvastatin lowered LDL-C to $62 \mathrm{mg} / \mathrm{dl}$ (49\% decrease, $\mathrm{P}<$ 0.001 ) and $40 \mathrm{mg}$ of atorvastatin lowered LDL-C to $70 \mathrm{mg} / \mathrm{dl}$ (40\% decrease, $\mathrm{P}<0.001$ ), and moderate doses of both statins could regress plaque effectively, and plaque was increased in $34 \%$ of patients with follow-up LDL-C $>70 \mathrm{mg} / \mathrm{dl}$ and in $15 \%$ of patients with follow-up LDL-C $\leq 70 \mathrm{mg} / \mathrm{dl}$, and follow-up LDL-C was the independent predictor of plaque increase, as in previous studies. In the present study, changes of TAV and PAV from baseline to follow-up were not significantly different between the rosuvastatin and atorvastatin groups. The present results suggest that effective LDL-C lowering and plaque regression can be achieved using only moderate doses of statins, and that different types of statins with similar LDL-C-lowering effects have similar effects on plaque regression in Korean patients with intermediate coronary stenosis.

CRP has emerged as a simple tool for detecting systemic inflammation. ${ }^{13,14} \mathrm{~A}$ previous study demonstrated that CRP was strongly associated with atherosclerosis measured at various sites in the arterial tree. ${ }^{15}$ Several mechanisms have been described by which CRP and other inflammatory mediators may be actively involved in atherogenesis. ${ }^{16} \mathrm{CRP}$ is produced by smooth muscle cells of atherosclerotic lesions, ${ }^{17}$ and the locally produced CRP could directly participate in atherogenesis and the development of cardiovascular complications. In the present study, plaque was increased in $38 \%$ of patients 


\begin{tabular}{|c|c|c|c|}
\hline & $\begin{array}{l}\text { Plaque increase } \\
\qquad(n=29)\end{array}$ & $\begin{array}{l}\text { Plaque non-increase } \\
\qquad(\mathrm{n}=99)\end{array}$ & $P$ value \\
\hline Target coronary artery $(n)$ & & & 0.3 \\
\hline Left main & $3(10)$ & $5(5)$ & \\
\hline Left anterior descending & $16(55)$ & $55(56)$ & \\
\hline Left circumflex & $1(3)$ & $14(14)$ & \\
\hline Right & 9 (31) & $25(25)$ & \\
\hline Lesion location (n) & & & 0.5 \\
\hline Proximal & $16(55)$ & $49(49)$ & \\
\hline Middle & $9(31)$ & $32(32)$ & \\
\hline Distal & $4(14)$ & $18(18)$ & \\
\hline $\mathrm{RD}(\mathrm{mm})$ & $3.32 \pm 0.58$ & $3.25 \pm 0.48$ & 0.2 \\
\hline MLD (mm) & $1.75 \pm 0.54$ & $1.80 \pm 0.44$ & 0.18 \\
\hline Percent diameter stenosis (\%) & $47 \pm 13$ & $45 \pm 10$ & 0.6 \\
\hline IVUS lesion length (mm) & $17 \pm 15$ & $20 \pm 15$ & 0.7 \\
\hline Plaque morphology (n) & & & 0.3 \\
\hline Soft & $19(66)$ & $64(65)$ & \\
\hline Fibrotic & $4(14)$ & $4(4)$ & \\
\hline Calcified & $2(7)$ & $7(7)$ & \\
\hline Mixed & $4(14)$ & $24(24)$ & \\
\hline EEM volume $\left(\mathrm{mm}^{3}\right)$ & $304 \pm 202$ & $385 \pm 221$ & 0.076 \\
\hline Lumen volume $\left(\mathrm{mm}^{3}\right)$ & $157 \pm 111$ & $198 \pm 118$ & 0.095 \\
\hline $\operatorname{TAV}\left(\mathrm{mm}^{3}\right)$ & $147 \pm 95$ & $187 \pm 108$ & 0.074 \\
\hline PAV (\%) & $49 \pm 7$ & $49 \pm 6$ & 1.0 \\
\hline
\end{tabular}

Data are given as mean \pm SD or $n(\%)$.

Abbreviations see in Table 2.

\begin{tabular}{|c|c|c|c|}
\hline & $\begin{array}{l}\text { Plaque increase } \\
\qquad(n=29)\end{array}$ & $\begin{array}{l}\text { Plaque non- increase } \\
\qquad(n=99)\end{array}$ & $P$ value \\
\hline Total cholesterol (mg/dl) & $146 \pm 35$ & $123 \pm 25$ & $<0.001$ \\
\hline Triglyceride (mg/dl) & $144 \pm 280$ & $85 \pm 44$ & 0.046 \\
\hline LDL-C (mg/dl) & $78 \pm 24$ & $63 \pm 21$ & 0.002 \\
\hline HDL-C (mg/dl) & $49 \pm 14$ & $47 \pm 12$ & 0.4 \\
\hline Apoprotein A1 (mg/dl) & $128 \pm 23$ & $128 \pm 20$ & 0.9 \\
\hline Apoprotein B (mg/dl) & $70 \pm 16$ & $57 \pm 16$ & $<0.001$ \\
\hline Apoprotein B/A1 & $0.56 \pm 0.16$ & $0.45 \pm 0.14$ & 0.001 \\
\hline Lipoprotein (a) (mg/dl) & $30 \pm 19$ & $31 \pm 29$ & 0.9 \\
\hline $\mathrm{hs}-\mathrm{CRP}(\mathrm{mg} / \mathrm{dl})$ & $0.16 \pm 0.43$ & $0.12 \pm 0.31$ & 0.7 \\
\hline EEM volume $\left(\mathrm{mm}^{3}\right)$ & $305 \pm 201$ & $380 \pm 221$ & 0.10 \\
\hline Lumen volume $\left(\mathrm{mm}^{3}\right)$ & $154 \pm 111$ & $199 \pm 120$ & 0.074 \\
\hline $\operatorname{TAV}\left(\mathrm{mm}^{3}\right)$ & $151 \pm 95$ & $180 \pm 105$ & 0.17 \\
\hline PAV (\%) & $50 \pm 7$ & $48 \pm 7$ & 0.10 \\
\hline$\Delta$ Total cholesterol $(\mathrm{mg} / \mathrm{dl})$ & $-46 \pm 48$ & $-58 \pm 41$ & 0.18 \\
\hline$\Delta$ Triglyceride $(\mathrm{mg} / \mathrm{dl})$ & $-1 \pm 146$ & $-33 \pm 71$ & 0.11 \\
\hline$\Delta \mathrm{LDL}-\mathrm{C}(\mathrm{mg} / \mathrm{dl})$ & $-49 \pm 36$ & $-55 \pm 38$ & 0.4 \\
\hline$\Delta \mathrm{HDL}-\mathrm{C}(\mathrm{mg} / \mathrm{dl})$ & $-1.0 \pm 10.3$ & $-0.8 \pm 10.2$ & 0.9 \\
\hline$\Delta$ Apoprotein A1 (mg/dl) & $+0.5 \pm 22.0$ & $+0.5 \pm 21.3$ & 1.0 \\
\hline$\Delta$ Apoprotein B (mg/dl) & $-31 \pm 22$ & $-37 \pm 24$ & 0.3 \\
\hline$\Delta$ Lipoprotein (a) (mg/dl) & $+2.2 \pm 10.4$ & $+4.8 \pm 12.9$ & 0.3 \\
\hline$\Delta \mathrm{hs}-\mathrm{CRP}(\mathrm{mg} / \mathrm{dl})$ & $-1.27 \pm 2.80$ & $-0.43 \pm 1.18$ & 0.2 \\
\hline$\Delta$ EEM volume $\left(\mathrm{mm}^{3}\right)$ & $+1.3 \pm 5.6$ & $-5.6 \pm 8.9$ & $<0.001$ \\
\hline$\Delta$ Lumen volume $\left(\mathrm{mm}^{3}\right)$ & $-2.6 \pm 5.7$ & $+1.0 \pm 7.5$ & 0.021 \\
\hline$\Delta \operatorname{TAV}\left(\mathrm{mm}^{3}\right)$ & $+3.8 \pm 2.9$ & $-6.3 \pm 6.2$ & $<0.001$ \\
\hline$\triangle \mathrm{PAV}(\%)$ & $+1.4 \pm 1.7$ & $-1.0 \pm 1.9$ & $<0.001$ \\
\hline
\end{tabular}

Abbreviations see in Tables 1,2. 
(A)

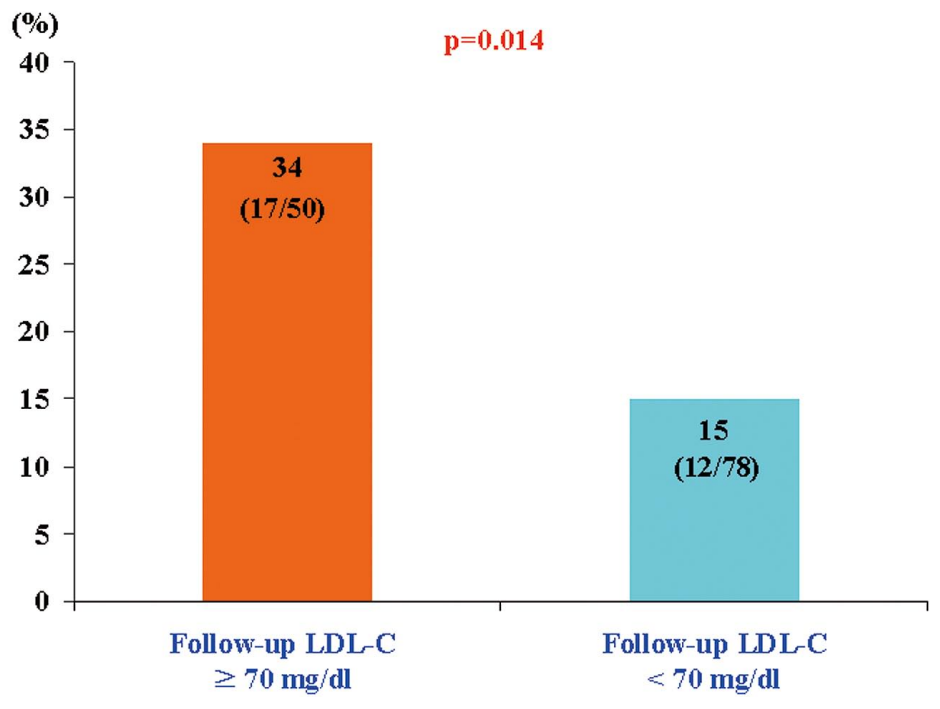

(B)
(\%)
$p=0.020$

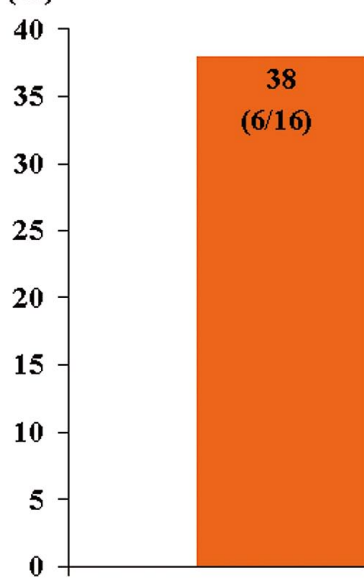

Baseline hs-CRP

$\geq 1.0 \mathrm{mg} / \mathrm{dl}$

Baseline hs-CRP

$<1.0 \mathrm{mg} / \mathrm{dl}$

(C)

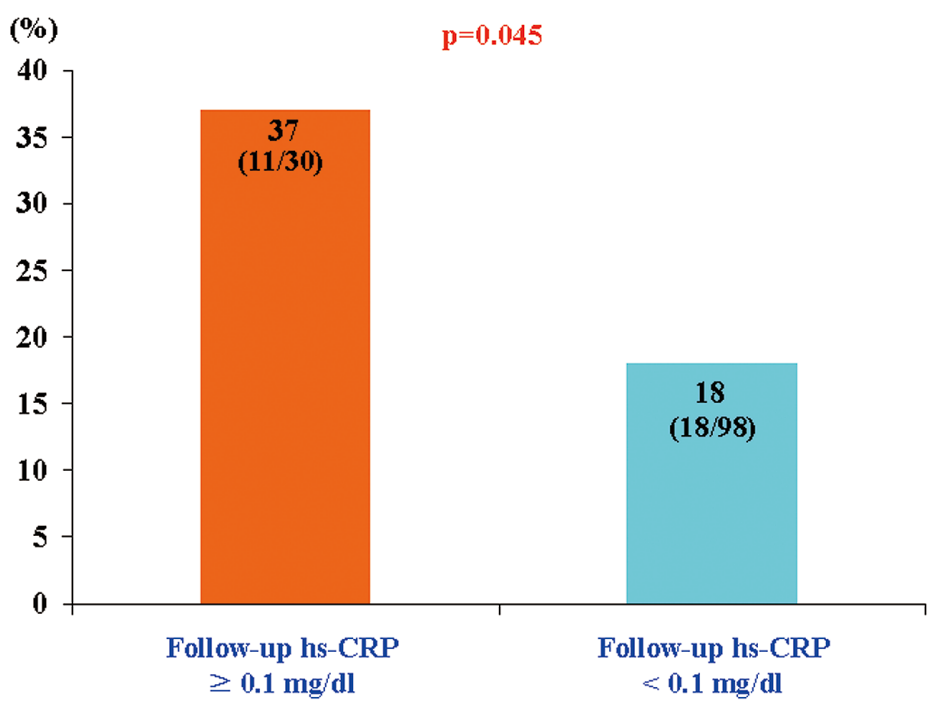

Figure 2. Plaque increase rate according to (A) follow-up low-density lipoprotein cholesterol (LDL-C), (B) baseline high-sensitivity C-reactive protein (hs-CRP), and (C) follow-up hs-CRP levels. 
with baseline hs-CRP $\geq 1.0 \mathrm{mg} / \mathrm{dl}$ and in $21 \%$ of patients with baseline hs-CRP $<1.0 \mathrm{mg} / \mathrm{dl}$, and plaque was increased in $37 \%$ of patients with follow-up hs-CRP $\geq 0.1 \mathrm{mg} / \mathrm{dl}$ and in $18 \%$ of patients with follow-up hs-CRP $<0.1 \mathrm{mg} / \mathrm{dl}$, and baseline hs-CRP was associated with plaque increase at followup, and the reduction of hs-CRP and plaque decrease from baseline to follow-up were similar in the rosuvastatin and atorvastatin groups. A previous experimental study has demonstrated that CRP accelerates the progression of atherosclerosis in apolipoprotein E-deficient mice. ${ }^{18} \mathrm{CRP}$ is related to the progression of coronary atherosclerosis ${ }^{19,20}$ and to peripheral atherosclerosis. ${ }^{21-24}$ The present results have demonstrated a relationship between levels of circulating inflammatory markers and risk of progressive atherosclerosis in Korean patients with intermediate coronary stenosis. Moderate doses of statins might be sufficient to reduce LDL-C and hs-CRP and to regress plaque more effectively in Asian patients compared with Caucasian patients.

\section{Study Limitations}

First, this was a single-center study and was based on a small sample, thus raising the possibility of selection bias. Second, serial follow-up of serum hs-CRP level was not done. Therefore, we did not demonstrate the impact of sequential change of hs-CRP level on plaque progression or regression. Third, plaque morphology was assessed visually using grayscale IVUS, which has significant limitations in assessing plaque composition. At present, radiofrequency analysis has become available for further plaque characterization. Fourth, the mean follow-up period was only 11 months, longer-term IVUS follow-up data were not collected.

\section{Conclusions}

Moderate doses of rosuvastatin and atorvastatin could contribute to plaque regression. Follow-up LDL-C and baseline hs-CRP are associated with plaque progression in Korean patients with intermediate coronary stenosis. Different types of statins with similar efficacy in LDL-C and hs-CRP reduction have similar effects on plaque regression at follow-up.

\section{Acknowledgments}

This study was supported by a grant from the Korea Healthcare technology R\&D project (A084869), Ministry for Health, Welfare and Family Affairs, Republic of Korea.

\section{Disclosures}

There are no potential conflicts to declare.

\section{References}

1. Cannon CP, Braunwald E, McCabe CH, Rader DJ, Rouleau JL, Belder R, et al. Pravastatin or Atorvastatin Evaluation and Infection Therapy-Thrombolysis in Myocardial Infarction 22 Investigators: Intensive versus moderate lipid lowering with statins after acute coronary syndromes. N Engl J Med 2004; 350: 1495 - 1504.

2. Kasai T, Miyauchi K, Kajimoto K, Kubota N, Kurata T, Amano A, et al. The impact of pravastatin therapy on long-term outcome in patients with metabolic syndrome undergoing complete coronary revascularization. Circ J 2009; 73: 2104-2019.

3. Nissen SE, Tuzcu EM, Schoenhagen P, Brown BG, Ganz P, Vogel RA, et al; REVERSAL Investigators. Effect of intensive compared with moderate lipid-lowering therapy on progression of coronary atherosclerosis: A randomized controlled trial. JAMA 2004; 291: $1071-1080$.

4. Takayama T, Hiro T, Yamagishi M, Daida H, Hirayama A, Saito $\mathrm{S}$, et al; COSMOS Investigators. Effect of rosuvastatin on coronary atheroma in stable coronary artery disease: Multicenter coronary atherosclerosis study measuring effects of rosuvastatin using intra- vascular ultrasound in Japanese subjects (COSMOS). Circ $J$ 2009; 73: $2110-2117$.

5. Toi T, Taguchi I, Yoneda S, Kageyama M, Kikuchi A, Tokura M, et al. Early effect of lipid-lowering therapy with pitavastatin on regression of coronary atherosclerotic plaque: Comparison with atorvastatin. Circ J 2009; 73: 1466-1472.

6. Nissen SE, Tuzcu EM, Schoenhagen P, Crowe T, Sasiela WJ, Tsai J, et al. Reversal of Atherosclerosis with Aggressive Lipid Lowering (REVERSAL) Investigators: Statin therapy, LDL cholesterol, Creactive protein, and coronary artery disease. $N$ Engl J Med 2005; 352: $29-38$

7. Nissen SE, Nicholls SJ, Sipahi I, Libby P, Raichlen JS, Ballantyne $\mathrm{CM}$, et al; ASTEROID Investigators. Effect of very high-intensity statin therapy on regression of coronary atherosclerosis: The ASTEROID trial. JAMA 2006; 295: 1556-1565.

8. Nicholls SJ, Tuzcu EM, Sipahi I, Grasso AW, Schoenhagen P, Hu T, et al. Statins, high-density lipoprotein cholesterol, and regression of coronary atherosclerosis. JAMA 2007; 297: 499-508.

9. Roberts WL, Moulton L, Law TC, Farrow G, Cooper-Anderson M, Savory J, et al. Evaluation of nine automated high-sensitivity Creactive protein methods: Implications for clinical and epidemiological applications. Part 2. Clin Chem 2001; 47: 418-425.

10. Reiber JH, van der Zwet PM, Koning G, von Land CD, van Meurs $\mathrm{B}$, Gerbrands JJ, et al. Accuracy and precision of quantitative digital coronary arteriography: Observer-, short-, and medium-term variabilities. Cathet Cardiovasc Diagn 1993; 28: 187-198.

11. Mintz GS, Nissen SE, Anderson WD, Bailey SR, Erbel R, Fitzgerald PJ, et al. American College of Cardiology clinical expert consensus document on standards for acquisition, measurement and reporting of intravascular ultrasound studies (IVUS): A report of the American College of Cardiology Task Force on Clinical Expert Consensus Documents. J Am Coll Cardiol 2001; 37: 1478-1492.

12. Nissen SE, Yock P. Intravascular ultrasound: Novel pathophysiological insights and current clinical applications. Circulation 2001; 103: $604-616$.

13. Ridker PM, Cannon CP, Morrow D, Rifai N, Rose LM, McCabe $\mathrm{CH}$, et al. Pravastatin or Atorvastatin Evaluation and Infection Therapy-Thrombolysis in Myocardial Infarction 22 (PROVE ITTIMI 22) Investigators: C-reactive protein levels and outcomes after statin therapy. N Engl J Med 2005; 352: 20-28.

14. Morrow DA, Braunwald E. Future of biomarkers in acute coronary syndromes: Moving toward a multimarker strategy. Circulation 2003; 108: 250-252.

15. van der Meer IM, de Maat MP, Bots ML, Breteler MM, Meijer J, Kiliaan AJ, et al. Inflammatory mediators and cell adhesion molecules as indicators of severity of atherosclerosis: The Rotterdam Study. Arterioscler Thromb Vasc Biol 2002; 22: 838-842.

16. Libby P, Ridker PM, Maseri A. Inflammation and atherosclerosis. Circulation 2002; 105: 1135-1143.

17. Jabs WJ, Theissing E, Nitschke M, Bechtel JF, Duchrow M, Mohamed S, et al. Local generation of C-reactive protein in diseased coronary artery venous bypass grafts and normal vascular tissue. Circulation 2003; 108: 1428-1431.

18. Paul A, Ko KW, Li L, Yechoor V, McCrory MA, Szalai AJ, et al. C-reactive protein accelerates the progression of atherosclerosis in apolipoprotein E-deficient mice. Circulation 2004; 109: 647-655.

19. Nakachi T, Kosuge M, Hibi K, Ebina T, Hashiba K, Mitsuhashi T, et al. C-reactive protein elevation and rapid angiographic progression of nonculprit lesion in patients with non-ST-segment elevation acute coronary syndrome. Circ J 2008; 72: 1953-1959.

20. Imai K, Okura H, Kume T, Yamada R, Miyamoto Y, Kawamoto T, et al. C-reactive protein predicts non-target lesion revascularization and cardiac events following percutaneous coronary intervention in patients with angina pectoris. J Cardiol 2009; 53: 388-395.

21. Elias-Smale SE, Kardys I, Oudkerk M, Hofman A, Witteman JC. C-reactive protein is related to extent and progression of coronary and extra-coronary atherosclerosis; results from the Rotterdam study. Atherosclerosis 2007; 195: e195-e202.

22. Arenillas JF, Alvarez-Sabín J, Molina CA, Chacón P, FernándezCadenas I, Ribó M, et al. Progression of symptomatic intracranial large artery atherosclerosis is associated with a proinflammatory state and impaired fibrinolysis. Stroke 2008; 39: 1456-1463.

23. Tzoulaki I, Murray GD, Lee AJ, Rumley A, Lowe GD, Fowkes FG. C-reactive protein, interleukin-6, and soluble adhesion molecules as predictors of progressive peripheral atherosclerosis in the general population: Edinburgh Artery Study. Circulation 2005; 112: 976-983.

24. Hashimoto H, Kitagawa K, Hougaku H, Etani H, Hori M. Relationship between C-reactive protein and progression of early carotid atherosclerosis in hypertensive subjects. Stroke 2004; 35: 1625-1630. 